\title{
Commentary \\ Spreading (Dis)Trust: Covid-19 Misinformation and Government Intervention in Italy
}

\author{
Alessandro Lovari \\ Department of Political and Social Sciences, University of Cagliari, 073100 Cagliari, Italy; E-Mail: alessandro.lovari@unica.it
}

Submitted: 30 April 2020 | Accepted: 25 May 2020 | Published: 26 June 2020

\begin{abstract}
The commentary focuses on the spread of Covid-19 misinformation in Italy, highlighting the dynamics that have impacted on its pandemic communication. Italy has recently been affected by a progressive erosion of trust in public institutions and a general state of information crisis regarding matters of health and science. In this context, the politicization of health issues and a growing use of social media to confront the Coronavirus "infodemic" have led the Italian Ministry of Health to play a strategic role in using its official Facebook page to mitigate the spread of misinformation and to offer updates to online publics. Despite this prompt intervention, which increased the visibility and reliability of public health communication, coordinated efforts involving different institutions, media and digital platform companies still seem necessary to reduce the impact of misinformation, as using a multichannel strategy helps avoid increasing social and technological disparities at a time of crisis.
\end{abstract}

\section{Keywords}

Coronavirus; Covid-19; emergency; health communication; Italy; misinformation; public communication; social media

\section{Issue}

This commentary is part of the issue "Health and Science Controversies in the Digital World: News, Mis/Disinformation and Public Engagement" edited by An Nguyen (Bournemouth University, UK) and Daniel Catalan (University Carlos III of Madrid, Spain).

(C) 2020 by the author; licensee Cogitatio (Lisbon, Portugal). This article is licensed under a Creative Commons Attribution 4.0 International License (CC BY).

\section{Introduction}

Originating in December 2019 in Wuhan, Covid-19 rapidly spread across China due to the interconnected systems of globalized modernity (Sastry \& Dutta, 2012), where everybody is a plane ride away from chains of lethal transmission (Ungar, 2001). As Italy became the first Western country to be affected by Covid-19, it immediately was involved in an "infodemic" characterized by a mix of facts, fears, rumors and speculations.

The lack of information about the virus and its consequences for people's safety, the uncertainty as to how it might be transmitted, and the dissemination of various types of misinformation about Covid-19 worked together to increase this stream of infodemic. The chaotic flow of communication compounds an information crisis that has dogged Italy over the last decade, with antiscience movements having gained visibility in the digi- tal realm, being often covered by the mass media and heavily politicized by populist parties (Lovari, Martino, \& Righetti, 2020).

When, on 20 February, a 38-year-old Italian man was placed in intensive care in Codogno (North of Italy) and tested positive for the virus, the country was immediately up against an emergency from a health and communication point of view. The following weeks saw a rollercoaster of polarized interventions and sentiments, accelerated by constant public disputes between scientists and politicians, spectacularized by mainstream media, and fueled by partisan interests. This anxiogenic situation escorted the country until 9 March when the Prime Minister, Giuseppe Conte, declared a lockdown in order to stop the spread of the virus. A few days later, the Word Health Organization (WHO) characterized Covid-19 as a pandemic, the first caused by a Coronavirus and the first entrenched on social media. 
In this framework, the commentary focuses on the main characteristics of the Italian infodemic, with specific attention to misinformation about Covid-19 on social media, and highlights how the Italian Ministry of Health (IMH) has faced this online.

\section{The Italian Context}

In recent years, Italy has increasingly dealt with antiscience movements that have questioned the value of experts and scientists and that represent one of the main effects of a postmodern conception of health (Kata, 2012). This process is related to socio-cultural transformations which have led to a growing public engagement with scientific questions and increasing intersections between expert knowledge and citizens' responses, which foster a demand for non-expert participation in health intervention processes and a less passive attitude towards the professionals' authority. In this respect, the relationship between science and lay publics has profoundly changed, impacting on the credibility of public health institutions. The development of digital technologies and the pervasiveness of personal media have enhanced this process, challenging the role of governments and institutions. This demands the adoption of new communication models not only to relate with media, but also to converse with different publics who are now enabled to make their voices heard by medical experts and health institutions on social media (Lovari, 2017).

In this context, Italy suffers from a general lack of trust in public institutions. Italy was one of the six countries to register an extreme decline in trust, with an overall decrease of 21 points in one year, and with government and media being the least trusted institutions (Edelman, 2018). This lack of trust is also marked in relation to science and scientists. Italians were found to be more skeptical than other European citizens about the beneficial impact of technoscience (Eurobarometer, 2010). Moreover, Italians have much less confidence in the impact of technological and scientific innovations on their health $(51 \%)$, in comparison with the other countries (76.5\% on average). Lower rates are also reported for trust in scientists (56.9\%), especially when scientific studies deal with controversial research funded by private companies (54\%; Eurobarometer, 2014).

This skepticism was clearly manifested in the controversy which has raged in Italy over the issue of vaccinations, fueled by the activism of the anti-vax movements on social media (Tipaldo, 2019), a debate which reveals starkly polarized user opinions, often accompanied by echo-chamber effects (Schmidt, Zollo, Scala, Betsch, \& Quattrociocchi, 2018). This process was accelerated by the politicization of the topic, which meshed with the spread of populist anti-elitism movements and the diffusion of conspiracy theories (Mancosu, Vassallo, \& Vezzoni, 2017), helping to erode the lay-public's confidence in scientific and health facts. In facing this challenge, the Italian Ministry of Health and public health authorities decided to use social media to make their voices heard online and counteract the misinformation, but with mixed results and a lack of coordination at central and regional level (Lovari, 2017).

This information crisis was the fertile humus for the Covid-19 infodemic that struck Italy in February 2020. Uncertainty, distrust and fears were further accentuated by the role played by several Italian physicians who publicly started talking about the virus on their social media profiles or were interviewed by mainstream media in news and talk shows. Discordant medical voices were embedded and spectacularized by media logics, becoming spreadable content on digital platforms, often politicized or associated with fake news and conspiracy theories, thus increasing distrust among connected publics.

\section{Misinformation Meets Covid-19}

The uncertainty surrounding the etiology and the consequences of the virus gave rise to a cacophony of voices, in which institutional communication was often misaligned with media coverage and with an indistinguishable mix of misinformation, unverified rumors and intentionally manipulated disinformation (Larson, 2020). The quantity of information about Coronavirus rapidly increased online. According to social media monitoring by the Vaccine Confidence Project, 3.08 million messages about Covid-19 were disseminated daily between January and mid-March 2020 (Larson, 2020). Different types of misinformation accounted for a sizeable portion of the content. These rumors and hoaxes spread rapidly on the social web, disturbing the authenticity balance of the communication ecosystems. This factor quickly pushed governments to commit to curbing the spread of misinformation to avoid the risk of behaviors that are potentially harmful to the population. For instance, a study analyzing misinformation rated false by independent fact-checkers reported that false content was mostly spread on social media (88\%), assuming various textual and visual reconfigurations. Moreover, the most recurrent claim concerned policies or interventions taken by public authorities to tackle the spread of Covid-19, alleging that health organizations and governments had not fully succeeded in offering reliable information in response to demands from the public (Brennen, Simon, Howard, \& Nielsen, 2020).

Italy was totally involved in this infodemic. For instance, a report highlighted that the term "Coronavirus" accounted for 575,000 searches by Italian users out of a monthly total of 950,000 (Sciuto \& Paoletti, 2020). In a study by Edelman (2020), Italy was the country with the highest percentage of people accessing news and information about the virus on a daily basis (58\%), overtaking countries like Korea, Japan and US. AGCOM (2020) found that, as a proportion of disinformation published online, Coronavirus contents rose from $5 \%$ in early January to $46 \%$ in late March. On social media, in particular, Coronavirus posts increased to $36 \%$ of all messages produced by disinformation sources. Part of this 
disinformation seemed to be linked to conspiracy theories and false reports and claims from actors close to Russia and China, aiming to undermine alliances within the European Union when Italy was facing the first phase of the emergency (EEAS, 2020). Despite the commitment of digital companies to stop the spread of misinformation, and notwithstanding the strategic partnerships forged between the WHO and the health ministries of several countries, fake news remained difficult to contain. One study described how misinformation was not uniformly removed by Facebook (Avaaz, 2020): 68\% of Italian-language misinformation was not labeled to alert users to Covid-19 fake news. Moreover, $21 \%$ of the Italian misinformation posts fell into the category of "harmful content" that Facebook has committed to remove, but these posts were still present in early April.

\section{The Role of The Italian Ministry of Health}

It was in this problematical situation that the Italian Ministry of Health assumed a central role by starting to produce messages about the virus in an attempt both to respond to growing demands from citizens and to stem the tide of inaccurate information. Specific attention was devoted to the ministerial website with a Covid-19 section, both in Italian and English, with a thematic page to counter misinformation, named "Attenti alle bufale" (Beware of hoaxes), which disproves more than 50 Coronavirus hoaxes circulating on social media.

A key effort was addressed to the Italian Ministry of Health Facebook page. With the emergency, the number of likers rose from 61,196 on 30 January to 409,145 on April 3, showing the need felt by users to find a reliable institutional source about the virus, but also the strategic function played by this page in mitigating the infodemic. In those two months, the page published 301 posts, $94 \%$ of which were about Covid-19, turning into a thematic page to face the emergency. The engagement rate reached an average of 2,652 likes, 1,983 sharing, and 378 comments per post. As regards the contents, the Italian Ministry of Health created campaigns about Coronavirus (21.9\%), involving famous people and digital influencers, and using specific hashtags (e.g., \#iorestoacasa). Messages countering fake news occupied $7.1 \%$ of the institutional flow. These posts were enriched with emoticons, infographics and social cards, frequently integrating the words falso (false) or "fake news" in visuals, and linking to the Covid-19 section in the ministerial website. Several posts (12.4\%) explained the measures adopted by the Italian government in order to ensure appropriate behaviors during the lockdown. Furthermore, the contents did not feature a marked incidence of politicians (8.9\%), thus reducing the risk of a politicization of the virus, one of the main concerns of the population (Edelman, 2020). One negative aspect was the shortage of replies to users' comments on the page (less than $5 \%$ ), leaving people's queries largely unanswered and thus possibly undermining trust in this institution.

\section{Conclusions}

In this first social media pandemic, the Italian Ministry of Health has adopted specific digital communication strategies to face the Covid-19 emergency, devoting intense efforts to keeping the citizen constantly informed and to reducing misinformation, using data and visuals to make the messages easily understood. In February, the Italian Ministry of Health signed partnerships with Facebook and other digital companies to convey users' searches on the ministerial channels. In April, the Italian government launched a specific task force to promote collaboration with fact-checkers and to encourage citizens' activism in signaling misinformation.

From the point of view of public health communication, all these actions proved useful in facing the acute phase of the infodemic, raising the visibility of official sources and aiming to restore credibility by reconnecting with citizens. In this period of fear and uncertainty, a transparent, strategic and proactive use of social media by public health organizations seems to be fundamental to increasing trust and reducing the impact of false narratives. In states of emergency, institutions should also depoliticize health topics on social media channels to reduce further polarization and to limit the rise of new conflicts, both already fostered by the nature of social media and their algorithms. Furthermore, to flatten the curve of misinformation it seems necessary to make constant and coordinated efforts involving authorities, mass media and digital companies. For instance, the media could give a greater voice to journalists specialized in health and science topics in order to contextualize data and statistics about the virus and to decrease the spectacularization of these themes merely to gain audience or clicks. Digital companies should continue to collaborate with governments to stop the spread of Covid-19 misinformation, elevating authoritative content and paying strategic attention to cultural and linguistic factors that could enhance the dissemination of fake news. Furthermore, misinformation should be counteracted through an extensive investment in media education and digital literacy to develop a critical awareness of the use of media and digital technologies. In this respect, media education should involve society as a whole in order to increase the skills and competences necessary to interact effectively while negotiating the pitfalls of misinformation. Lastly, it is important that public health institutions should continue to inform citizens with offline tools and traditional media, using a multichannel strategy, so as not to exclude parts of the population or to increase technological and social disparities.

\section{Acknowledgments}

A special thank to the editors of this thematic issue for their attention and interest in my research. 


\section{Conflict of Interests}

The author declares no conflict of interests.

\section{References}

AGCOM. (2020). Osservatorio sulla disinformazione online. Speciale Coronavirus [Observatory on disinformation. Special on Coronavirus]. AGCOM. Retrieved from https://www.agcom.it/osservatoriosulla-disinformazione-online

Avaaz. (2020). How Facebook can flatten the curve of the Coronavirus Infodemic. Avaaz. Retrieved from https://secure.avaaz.org/campaign/en/facebook_ coronavirus misinformation

Brennen, S., Simon, F. M., Howard, P. N., \& Nielsen, R. K. (2020). Types, sources, and claims of Covid-19 misinformation. Oxford: Reuters Institute for the Study of Journalism.

Edelman. (2018). Trust barometer. Chicago, IL: Edelman. Retrieved from https://www.edelman.com/sites/ g/files/aatuss191/files/2018-10/2018_Edelman Trust_Barometer_Global_Report_FEB.pdf

Edelman. (2020). Trust and the Coronavirus. Chicago, IL: Edelman. Retrieved from https://www.edelman. com/sites/g/files/aatuss191/files/2020-03/2020\% 20Edelman\%20Trust\%20Barometer\%20Brands\%20 and\%20the\%20Coronavirus.pdf

EEAS. (2020). Covid-19 disinformation. EEAS. Retrieved from https://euvsdisinfo.eu

Eurobarometer. (2010). Science and technology (Special Eurobarometer 340). Retrieved from https:// ec.europa.eu/commfrontoffice/publicopinion/ archives/ebs/ebs_340_en.pdf
Eurobarometer. (2014). Public perceptions of science, research and innovation (Special Eurobarometer 419). Retrieved from https://ec.europa.eu/ commfrontoffice/publicopinion/archives/ebs/ebs_ 419_en.pdf

Kata, A. (2012). Anti-vaccine activists, Web 2.0, and the postmodern paradigm. Vaccine, 30(25), 3778-3789.

Larson, H. J. (2020). Blocking information on Covid-19 can fuel the spread of misinformation. Nature, 58, 306.

Lovari, A. (2017). Social media e comunicazione della salute [Social media and health communication]. Milan: Guerini.

Lovari, A., Martino, V., \& Righetti, N. (2020). Blurred shots. Investigating the information crisis around vaccination in Italy. American Behavioral Scientist. Advance online publication. https://doi.org/10.1177/ 0002764220910245

Mancosu, M., Vassallo, S., \& Vezzoni, C. (2017). Believing in conspiracy theories. South European Society and Politics, 22(3), 327-344.

Sastry, S., \& Dutta, M. J. (2012). Public health, global surveillance, and the "emerging disease" worldview. Health Communication, 27, 519-532.

Schmidt, A. L., Zollo, F., Scala, A., Betsch, C., \& Quattrociocchi, W. (2018). Polarization of the vaccination debate on Facebook. Vaccine, 36(25), 3606-3612.

Sciuto, P., \& Paoletti, J. (2020). SEO Tester online/Quarzio Srl: Covid-19 Report, Retrieved from https://it.seotesteronline.com

Tipaldo, G. (2019). La società della pseudoscienza [The pseudoscience society]. Bologna: II Mulino.

Ungar, S. (2001). Moral panic versus the risk society. British Journal of Sociology, 52, 271-291.

\section{About the Author}

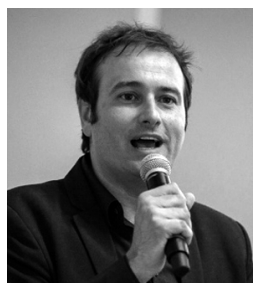

Alessandro Lovari is Assistant Professor of Sociology of Communication at the University of Cagliari (Italy). Lovari's research focuses on public communication, public relations, and health communication. He studies social media impact on organizations and citizens' behaviors and practices. Lovari is member of the scientific committee of the Italian Association of Public Sector Communication. He was Visiting Research Scholar at Purdue University, University of Cincinnati, University of South Carolina, and Virginia Commonwealth University (USA). His works appear in several books and international journals. 